\title{
APONTAMENTOS SOBRE A HISTÓRIA DA LEITURA
}

Cláudio DeNipoti*

Resumo: Este artigo busca revisar alguns dos caminhos percorridos por historiadores preocupados com a história da leitura, mostrando alguns resultados de suas pesquisa, bem como conclusões parciais desses autores quanto às formas da leitura e do ensino da leitura no passado.

Unitermos: história da leitura; historiografia.

Grande parte das atividades cotidianas corriqueiras, principalmente aquelas mais insuspeitas de terem sido inventadas e que, portanto, não merecem maiores considerações por parte dos historiadores, têm se mostrado um campo fértil de análise histórica. Dessa forma, a historicidade do amor pelos filhos, da paixão pelos balneários, e das atividades relacionadas à vida privada já foram descritas em trabalhos consagrados. (Badinter, 1985; Ariès \& Duby, 1991; Corbin, 1989).

De modo idêntico, uma das atividades hoje considerada das mais banais, ainda que permanecendo restrita à casta dos alfabetizados (divisão imposta por sua própria existência) teve sua história, se não menosprezada, no minimo negligenciada, pela historiografia brasileira recente. A leitura - a capacidade de reconhecer símbolos alfabéticos e também o hábito de fazê-lo regularmente - tem a sua história intimamente relacionada com a história do mundo como a conhecemos, já que, antes dos meios de transmissão do conhecimento da era da eletricidade surgirem, a leitura fora a única forma dessa transmissão

\footnotetext{
Professor do Departamento de História - Universidade Estadual de LondrinaLondrina/PR.
} 
DENIPOTI, C. Apontamentos sobre a história da leitura.

para além da tradição oral, da qual sente falta Walter Benjamin em seu narrado' (Benjamin, 1986).

A leitura passa a ser vista como um objeto possivel da história, em particular da história cultural, e tanto a leitura quanto sua historia podem ser vistas sob diferentes prismas. Ainda que tenhamos mais dúvidas que certezas quanto aos processos neurológicos envolvidos no ato de ler, há uma imensa carga cultural no desenvolver-se da leitura, que acompanha, pari passu, a própria história da cultura no Ocidente ${ }^{2}$

Neste artigo, procuraremos ver como alguns historiadores trataram a leitura como objeto de pesquisa e análise, utilizando-se de diversas abordagens, que vão da lingüística à história quantitativa, da crítica literária à antropologia cultural, confrontando os diversos momentos históricos e sociedades com as diferentes formas de leitura que foram desenvolvidas. Se tomarmos, por exemplo, o caso da Grécia Antiga, a leitura era designada por palavras que significavam tanto $o$ ato de reconhecer quanto falar. Assim,

mesmo o leitor solitário (... / näo lera]
silencioso: ele provavelmente llial à
meia voz, o que [reduzia] as distâncias
entre a leitura individual e a leitura
coletiva. Jamais se [lia] unicamente com
os olhos; mesmo nas bibliotecas, onde o
ruido deveria ser insuportóvel. Mesmo
quando se lestava] completamente só,
como vemos na comédia quando aquele
que recebia uma carta, a [lia] alto não

1 Para Benjamin, há dois tipos de narrador, que se interpenetram de múltiplas maneira, o narrador espacial, o viajante, que vê o mundo exótico, fora do local de origem (e quanto mais nos distanciamos no tempo, mais próximo está o exótico), e - homem que ganhou honestamente sua vida sem sair de seu pais e que conhece suas histórias e tradições. Os exemplos desses narradores são, respectivamente, o marinheiro comerciante e o camponês sedentário. (Benjamin, 1986: 199).

2. Evitarei aventurar-me sobre as diversas formas de leitura dos ideogramas orientais (chineses ou japoneses) e a leitura para além da tradição ocidental Sobre o processo de memorização que caracteriza a cultura chinesa e sua escrita, ver Spence, 1986. 
DENIPOTI, C. Apontamentos sobre a história da leitura.

somente porque leral necessário informar o público, mas também porque leral o costume (Canfora, 1989a: 927).

Há porém, um grande fosso entre ser capaz de reconhecer sinais alfabéticos e ler livros ou opúsculos mais ou menos longos. Ainda que os livros fossem objetos de circulação limitada na antigüidade grega, havia uma crescente preocupação com a formação de bibliotecas como a de Alexandria (Canfora, 1989b). Nas palavras de Políbio, se quiseres escrever a história sem perigos ou fadigas, tens de instalarte em uma cidade bem dotada de livros ou em qualquer lugar vizinho a uma biblioteca (Canfora, 1989a: 931).

O fenômeno da criação de bibliotecas contudo, não criara ao seu redor, nem na Grécia, nem em Roma, um universo de leitores. Em Atenas, segundo Aristóteles, apesar da circulação limitada de livros, a maioria dos atenienses, ainda que alfabetizada rudimentarmente, só se utilizava desse conhecimento para os negócios e para a administração do patrimônio e para a política (Canfora, 1989a, 930). Em Roma, a moda de grandes bibliotecas particulares iniciada por Silas e Lúculo no inicio do Império, também não significava uma generalização do hábito da leitura. A biblioteca de Lúculo continha essencialmente obras clássicas gregas, acessiveis somente aos eruditos romanos bilingües, como Cícero e o próprio Lúculo.

Eventualmente, próximo do fim do Império, essas bibliotecas particulares passaram a ser um aspecto decorativo do domus de alguns cidadãos romanos que, apesar do esforço - capitaneado por Cícero - de tradução para o latim dos clássicos, não tinham o habito de ler. Sêneca e Plínio, o moço, lamentavam a decadência do interesse pela leitura, tanto individual (nas bibliotecas particulares), quanto as leituras públicas, realizadas nos palácios e nas bibliotecas, como a de Alexandria (Canfora, 1989a: 936).

Podemos considerar aqui o quanto a leitura na antigüidade diferia do que entendemos por este termo se analisarmos, juntamente com Robert Darnton, a Ars Amatónia (Arte de amar) de Ovídio. Nesta, recomenda-se à mulher apaixonada que deseja fazer chegar uma carta a seu amante, que se utilize de vários meios, inclusive, caso; seu 
DENIPOTI, C. Apontamentos sobre a história da leitura.

guardião possa ver através de todos estes estratagemas, faça então com que sua confidente [uma criada, por exemplo] ofereça costas em lugar das placas e deixe que setu corpo se transforme em uma carta viva. Do que Damton conclui: Espera-se que o amante dispa a criada e leia seu corpo - não exatamente o tipo de comunicação que associamos hoje em dia a uma carta de amor. (Damton, 1989: 200).

Com o cristianismo, houve uma maior democratização da leitura no Império Romano (próxima àquela sonhada por utopistas atenienses muito tempo antes). Porém, essa alfabetização - não intencional, no sentido que não fora conduzida pelos sábios e estudiosos - estava intrinsecamente ligada à difusão do Novo-Testamento, sendo considerada até mesmo perigosa, já que os leitores agora não eram apenas os cidadãos, mas qualquer pessoa, inclusive colonos, camponeses e bárbaros (Canfora, 1989a: 936).

Assim, existe uma íntima conexão entre a difusão da leitura e aquela do Novo Testamento, no periodo de transição entre a antigüidade e a Idade Média, que possibilita com a que leitura, e suas consequêencias, como a alfabetização e a difusão do comércio e produção de livros. A religião cristã passa a fornecer o principal elemento de coesão para a leitura ocidental.

Foi em virtude do cristianismo que, durante a Idade Média, as técnicas pedagógicas de ensino da leitura se multiplicaram. A história da leitura nesse periodo é possibilitada pelo que remanesceu dessas técnicas. $O$ ensino da leitura era feito visando principalmente as orações e os textos religiosos, sendo as bibliotecas mantidas quase que exclusivamente nos mosteiros. Ás crianças do medievo, buscava-se ensinar o alfabeto através de tábuas, de micrografias, de bordados ou de utensílios domésticos nos quais se apresentavam as letras. A disposição destas em seqüências lineares, horizontais, verticais ou circulares, permitia que se efetuasse um aprendizado precoce da leitura. Buscava-se a identificação com as escrituras sagradas, fosse associando-se o alfabeto aos dez mandamentos, fosse através de uma pedagogia que se equiparasse temporalmente à criação. Por exemplo:

segundo a Civile Honesteté des

Enfants, publicada em Paris em 1560. 
DENIPOTI, C. Apontamentos sobre a história da leitura.

[... o primeiro dia lde ensinol era consagrado ao aprendizado das letras de ' $a$ ' $a$ ' $d$ ' - de onde a palavra 'abecedário'. No segundo dia, eram ensinadas as letras de ' $e$ ' $a$ ' $h$ ': no terceiro, as letras de ' $i$ ' a ' $m$ '; no quarto. as letras de ' $n$ ' $a$ ' $q$ ': no quinto, ' $r$ ' $a$ ' $t$ '; no sexto, ' $u$ ' a ' $z$ '; $e$ no sétimo dia, 'deve-se rever lodas as letras reunidas' (Alexandre-Bidon, 1989: 967).

Mas, também durante a ldade Média, a leitura era indissociável da palavra - e da repetição - particularmente no inicio do aprendizado, seguindo um dos textos mais utilizados no processo de ensino: o verso Domine, labia mea aperies [...], que significa, Senhor, abre meus lábios, [e minha boca publicará tuas palavras] (Alexandre-Bidon, 1989: 988).

Concomitantemente, o material que passa a ser oferecido à leitura foi radicalmente ampliado a partir de fins do século $X V$, com a invenção da imprensa por tipos móveis que, ao contrário das cópias manuscritas, facilitava a produção de grande número de exemplares de uma mesma obra, diminuindo também os custos de fabricação do livro e, portanto, seu preço final. Para dar uma idéia da amplitude desse processo, de 30.000 a 35.000 impressões diferentes [das que foram] executadas entre 1450 e 1500 chegaram até nós, representando cerca de 10.000 a 15.000 textos diferentes. Muito mais, talvez, se levássemos em conta impressões desaparecidas (Febvre \& Martin, 1992: 356).

Porém, não foi Gutemberg quem de fato revolucionou a leitura no Ocidente, já que, ao menos inicialmente, a prensa de tipos móveis não provocou nenhuma grande revolução na forma do livro ou no modo de leitura. As mudanças de forma, do rolo (volumen) para o livro organizado em páginas costuradas (códex), os sinais identificadores de páginas, as notas de rodapés, todos precederam a invenção da prensa (Chartier, 1988:16-18). 
DENIPOTI, C. Apontamentos sobre a história da leitura.

A grande revolução da leitura localiza-se, segundo Roger Chartier, a partir do século IX, nos mosteiros, e a partir do século XIII, nas universidades européias e a daí para a sociedade leiga. Em essência, é a leitura silenciosa a grande mudança no modo de ler que Chartier identifica como revolucionária:

A leitura silenciosa de fato estabelece
um relacionamento mais livre, mais
secreto e totalmente privado com a
palavra escrita. Permite uma leitura
mais rápida, que não é impelida pelas
complexidades da organização do livro e
as relaçóes estabelecidas entre o
discurso e as glosas, as citaçoses e os
comentários, o texto e o indice. Também
permite usos diferenciados do mesmo
livro: dado o contexto ritual ou social,
ele pode ser lido alto para ou com outras
pessoas, ou pode ser lido silenciosamente
para si mesmo no abrigo do estúdio, da
biblioteca ou do oratório (Chartier,
1988: $18-19$ ).

Assim, para Chartier, a revolução na leitura precedeu a revolução no livro. Esta última, substituiu, em principios da Idade Moderna, o livro manuscrito pelo livro impresso, composto com tipos móveis. $\mathrm{E}$ há ainda uma outra revolução anterior, aquela que substituiu o rolo de leitura pelo códex, tenha sido igualmente importante, mesmo se legitimamente imaginemos que a nova forma dada à palavra escrita foi trazida à tona por uma nova forma de leitura nas comunidades cristãs (Chartier, 1988: 19)

Desta forma, a leitura passara a ser uma atividade comum a uma fatia mais ampla da sociedade, fosse porque mais pessoas alfabetizadas - particularmente após a laicização do ensino iniciada na Revolução Francesa - passaram a ter possibilidades de adquirir livros, fosse porque a leitura, até fins do século XVIII, era muitas vezes a leitura publica, com dez leitores reunidos em torno do texto lido em voz alta: 
DENIPOTI, C. Apontamentos sobre a história da leitura.

a 'leitura' é aqui a audição de uma palonra leitora (Chartier, 1990: 124).

Acompanhando as pesquisas de Rolf Engelsing e David Hall, que chegaram a um modelo geral da leitura através de pesquisas independentes, podemos pensar o século XVIII como o de uma revolução na leitura. Da Idade Média até aproximadamente 1750 , havia uma forma intensiva de se ler alguns livros - a Bíblia, alguns almanaques e catecismos - várias e vária vezes, em voz alta $e \mathrm{em}$ gnupos. Depois de 1800, na Europa, estudada por Engelsing, lia-se extensivamente, todo o tipo de material, especialmente periódicos e jornais [...] apenas uma vez, correndo para o item seguinte. No caso da Nova Inglaterra, estudada por David Hall, há uma inundação de novos tipos de livros - novelas, jornais, variedades recentes e alegres de literatura infantil - que eram lidos avidamente, descartando uma coisa, assim que podiam encontrar outra (Darnton, 1989: 212-13)

As chaves para essa cultura são dadas pela descrição que um mercador de Boston elabora com relação a um livro sobre a santa ceia, de sua autoria, deixado em herança para seu filho. Era um livro fino $e$ pequeno, encadernado em couro, escrito por minha própria mão, o qual considero mais precioso que ouro, e que eu li e reli, creio, centenas e centenas de vezes... Deixo-o a ele e espero que ele nunca se desfaça [do livro] enquanto viver. Quais são, portanto, essas chaves: um modo de ler que envolvia reler certos textos - não uma ou duas vezes, mas 'centenas e centenas de vezes'; uma aura do livro como supremamente 'precioso' porque continha o dom da vida; o alto significado da alfabetização porque fornecia acesso a esse dom; o parentesco entre leitura, devoção e os sacramentos(Hall, 1989: 42).

Essa dualidade de formas pode ser vista no Dom Quixote, de Cervantes, quando Sancho decide contar histórias para seu amo para passar o tempo. Sua narrativa entrecortada por repetições e histórias paralelas, comentários e digressões, projetam o narrador na história $e$ remetem à situcção de momento (Chartier, 1992: 217). Tal forma de narrar irritou D. Quixote, habituado ao fluxo dos livros que lia até o ponto de desvairado excesso (Chartier, 1992: 218). Ele queria que a narrativa de Sancho fosse feita conforme as regras da escrita linear, 
DENIPOTI, C. Apontamentos sobre a história da leitura.

objetiva e hierárquica. A distância entre essas duas perspectivas de um leitor e a prática oral, da forma como Sancho a aprendeu, [era] intransponivel. (Chartier, 1992: 218).

O contato com a leitura era, portanto, para uma grande parcela da população, mediado por um leitor público, que se utilizava, no mais das vezes, de recursos típicos da tradição oral para tomar um livro interessante a seus ouvintes. Para tanto, se utilizavam também de vulgarizações de obras clássicas medievais (conhecidas na França como Bibliothéque Bleue ${ }^{3}$ ) organizadas pelos editores de forma a tomarem-se mais próximas da narrativa oral à qual os leitores a quem as obras eram destinadas estavam habituados (Chartier, 1990: 129).

Essa leitura popular realizava-se sob a forma de uma reunião, ao redor do fogo, na veillée ${ }^{4}$ ou na oficina de trabalho, enquanto as pessoas exerciam outras atividades. Um dentre eles que dominasse os rudimentos da leitura entretinha a todos com as aventuras contidas nesses livros, em muito semelhantes à literatura de cordel. (Damton, 1989: 215).

As colônias da Nova Inglaterra, nos séculos XVI e XVII foram, talvez, o local por excelência da manifestação da capacidade de leitura como elemento de coesão social e emancipação. Os colonos puritanos, baseados na premissa protestante de que cada cristão deveria ter livre acesso à leitura da Bíblia, construíram todo seu universo social e cultural sobre essa prerrogativa. Contudo, essa leitura era bastante

A Bibliotheque Blene tinha esse nome devido às capas azuis, padronizadas para baratear o custo da edição. Continha títulos clássicos medievais simplificados, e histórias de fácil aceitação popular. Fssa fórmula editorial, inventada pelos Oudot, em Troyes, no século XITI - que faz circular pelo reino livros de baixo preço, impressos em grande número e divulgados através da venda ambulante - conhece seu apogeu entre a época de Luis XV e aquela em que os amigos de Gregório constatam seu exito. Nesse periodo, aumenta o numero de editores de Troyes especializados no gênero, o repertório dos textos passados deste modo a livros cresce considerovelmente $e$ a sua difusão atinge um publico cada vez maior.(Chartier, 1990: 165).

${ }^{4}$ Reunião notuma, em celeiros e estábulos, principalmente durante o inverno, onde realizavam-se tarefas conjuntas e onde os jovens faziam a corte, enquanto os mais velhos conversavam e liam. 
DENIPOTI, C. Apontamentos sobre a histôria da leitura.

diferente daquilo que hoje entendemos como o ato de ler. Primeiramente, sendo a Bíblia o parâmetro máximo de leitura, ao mesmo tempo em que era $a$ palavra de Deus - ou seja, a verdade absoluta e incontestável - o texto escrito tendia a ser visto sob essa mesma aura de verdade. Nesse sentido, os escritores da Nova Inglaterra buscavam evocar para os livros que escreviam a aura da Palavra, para que os leitores respondessem a seus livros como se fossem tão sagrados quanto a Biblia (Hall, 1989: 29). Ainda, a leitura - aprendida bastante cedo, entre os três e quatro anos - era resultado de um processo de instrução que começava ouvindo-se os outros lerem em voz alta e memorizando-se certos textos (Hall, 1989: 29). O aprendizado era também realizado dentro do domicílio, tendo as mães como instrutoras ou, no máximo, professoras informais, donas das dame schools ${ }^{5}$, que ensinavam aos filhos de outras mulheres da mesma forma que a seus filhos. Esse aprendizado dava-se quase que invariavelmente a partir da Bíblia - particularmente o livro dos salmos - e de catecismos. A técnica mais empregada era a de repetir em voz alta, visando a memorização. Esse procedimento significava que as crianças estwam recitando de memória antes de compreenderem - ou em qualquer sentido real, lerem - os textos em sua frente (Hall, 1989: 37). O uso de textos religiosos, por sua vez, implicava em uma inseparável conexão entre a leitura e a religião. Esses textos sagrados, lidos em voz alta e congruentes com a tradição vemácula protestante de que a leitura das escrituras era a escuta e a visão da Palavra Divina, levavam a que a intermediação humana no processo de leitura fosse negada.

O que podemos verificar, nos estudos sobre a leitura no passado, é que há uma riqueza muito grande de fontes e possibilidades que, ao serem estudadas, permitem o acesso a diferenças culturais no tempo. Embora se tenha buscado um modelo de como a leitura era feita,

Escolas mantidas por mulheres, em suas próprias casas. Geralmente eram mulheres cujos filhos já haviam crescido, que se dedicavam a alfabetizar outras crianças da cidade ou regiấo.(HALL, 1989: 34-6). 
DENIPOTI, C. Apontamentos sobre a história da leitura.

mesmo essas situações modelares eram permeadas por nuances variadas. Nas palavras de Robert Damton,

a leitura não se desenvolveu em uma só

direção, a extensão. Assumiu muitas

formas diferentes entre diferentes grupos

sociais em diferentes épocas. Homens e

mulheres leram para salvar suas almas.

para melhorar seu comportamento, para

consertar suas máquinas, para seduzir

seus enamorados, para tomar

conhecimento dos acontecimentos de seu

tempo, e ainda, simplesmente, para se

divertir (Darnton, 1989:212).

A história da leitura, nas formas que os historiadores acima buscaram escrevê-la, é a busca por essas diferenças e suas implicações nas sociedades que as forjaram culturalmente.

\section{Referências Bibliográficas}

ABREU, Márcia, org. Leituras no Brasil. Campinas: Mercado de Letras, 1995.

ALEXANDRE-BIDON, Danièle, "La lettre volée; aprendre a lire a l'enfant au moyen age". Annales E.S.C., Jul./Aut., 1989a, 44 aneé, n.4. p. 953-993

ARIĖS, Philippe e DUBY, George, Org., História da vida privada; da Renascença ao século das Luzes. São Paulo: Companhia das Letras, 1991.

BADINTER, Elisabeth. Um amor conquistado; o mito do amor materno. Rio de Janeiro: Nova Fronteira, 1985. 
DENIPOTI, C. Apontamentos sobre a história da leitura.

BENJAMIN, Walter. "O narrador, considerações sobre a obra de Nicolai Leskov" In: Obras Escolhidas I. São Paulo: Brasiliense, 1986, p. 197-221.

CANFORA, Luciano. "Lire a Athènes et a Rome". Annales E.S.C., Jul./Aut., 1989a, 44 aneé, n.4. p. 925-937.

A biblioteca desaparecida; histórias da biblioteca de Alexandria. São Paulo: Companhia das Letras, 1989b.

CHARTIER, Roger. "Frenchness in the History of the book; from the history of publishing to the history of reading. Worchester: American Antiquarian Society, 1988.

. A história cultural, entre práticas e representações. Lisboa: Difel, 1990.

"Textos, impressões e leituras". In: HUNT, Lynn. A nova história cultural. São Paulo: Martins Fontes, 1992 p. 211-238.

CORBIN, Alain, $O$ território do vazio; a praia e o imaginário ocidental. São Paulo: Companhia das Letras, 1989.

DARNTON, Robert. "História da Leitura", In: BURKE, Peter, org. $A$ escrita da história; novas perspectivas. São Paulo: EDUNESP, 1989, p. 199-236.

. Edição e sedição. São Paulo: Companhia das Letras, 1992.

FEBVRE, Lucién \& MARTIN, Henry-Jean. O aparecimento do livro. São Paulo: Editora da Universidade Estadual Paulista/Hucitec, 1992.

HALL, David D. Worlds of wonder, days of judgment; popular religious belief in early New England. New York: Knopf, 1989.

SPENCE, Jonathan. O palácio da memória de Matteo Ricci; a história de uma viagem: da Europa da contra-reforma à China da dinastia Ming. São Paulo: Companhia das Letras, 1986 